\title{
The Urogynecology Section of the Polish Society of Gynecologists and Obstetricians guidelines on the management of non-neurogenic overactive bladder syndrome in women
}

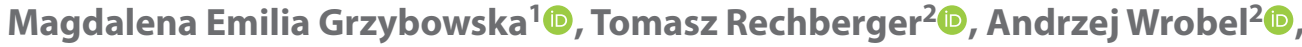 \\ Wlodzimierz Baranowski ${ }^{3}$, Klaudia Stangel-Wojcikiewicz ${ }^{4}$, Artur Rogowski ${ }^{5,}$ 6, $7 @$, \\ Tomasz Kluz $^{8}$ (D), Elzbieta Narojczyk-Swiesciak ${ }^{9}{ }^{\circ}$, Edyta Wlazlak ${ }^{10}{ }^{\circ}$, \\ Bartlomiej Burzynski ${ }^{11}$, Grzegorz Surkont ${ }^{10}$ (i) \\ ${ }^{1}$ Department of Gynecology, Gynecological Oncology and Gynecological Endocrinology, Medical University of Gdansk, Poland \\ 2II Department of Gynecology, Medical University of Lublin, Poland \\ ${ }^{3}$ Department of Gynecology and Gynecological Oncology, Military Medical Institute, Warsaw, Poland \\ ${ }^{4}$ Department of Gynecology and Oncology, Jagiellonian University Medical College, Cracow, Poland \\ ${ }^{5}$ Department of Gynecology, ,IIflancka" Specialist Hospital, Warsaw, Poland \\ ${ }^{6}$ Cardinal Stefan Wyszynski University in Warsaw, Faculty of Medicine, Collegium Medicum, Warsaw, Poland \\ ${ }^{7}$ Department of Obstetrics and Gynecology, Mother and Child Institute, Warsaw, Poland \\ ${ }^{8}$ Department of Gynecology and Obstetrics, Institute of Medical Sciences, Medical College of Rzeszow University, Rzeszow, Poland \\ ${ }^{9}$ Second Department of Obstetrics and Gynecology, The Center of Postgraduate Medical Education, Warsaw, Poland \\ ${ }^{10}$ Department of Operative Gynecology and Gynecologic Oncology, I Department of Gynecology and Obstetrics, \\ Medical University of Lodz, Poland \\ ${ }^{11}$ Department of Rehabilitation, Faculty of Health Sciences in Katowice, Medical University of Silesia, Katowice — Ochojec, Poland
}

\begin{abstract}
Objectives: The aim of the publication was to present the interdisciplinary guidelines of the Urogynecology Section of the Polish Society of Gynecologists and Obstetricians (PSGO) for the treatment of overactive bladder (OAB) syndrome based on the available literature, expert knowledge, and everyday practice.

Material and methods: A review of the literature, including current recommendations for the treatment of overactive bladder syndrome, urinary incontinence, urgency and mixed urinary incontinence, as well as the earlier recommendations of the PSGO Urogynecology Section, was conducted.

Results: Management of the patients with OAB is presented. Four lines of therapy were identified: 1) educating the patient, behavioral therapy with pelvic floor muscle training, 2) pharmacotherapy, 3) botulinum toxin injection and tibial nerve stimulation; and sacral nerve stimulation even though so far it has been used only in selected populations, 4) surgical intervention. The literature reports which provided supporting evidence and presented various aspects of the therapy were discussed. OAB pharmacotherapy-related issues which are vital in everyday clinical practice were presented.

Conclusions: A systematic review of the available guidelines and an analysis of $\mathrm{OAB}$ (including urgency urinary incontinence) management were conducted. The Polish Society of Gynecologists and Obstetricians issued the guidelines for the therapeutic management of OAB patients. The need for an individualized approach was emphasized.

Key words: overactive bladder; pharmacotherapy; behavioral therapy; physiotherapy; botulinum toxin; urinary incontinence
\end{abstract}




\section{INTRODUCTION}

The mission of the Urogynecology Section of the Polish Society of Gynecologists and Obstetricians (PSGO) is to promote the development of urogynecology in Poland, support education, and set evidence-based standards for the management of urogynecologic diseases. The Urogynecology Section issues certificates and awards credit points. The present update of the Guidelines concerns the treatment of the overactive bladder $(O A B)$ syndrome.

Various fields of medicine benefit from guidelines and recommendations for the management of numerous diseases issued by expert groups and associations. The aim of these guidelines is to set evidence-based standards and to present the current management of different diseases and conditions, in accordance with the global trends. Their content is based on the analysis of the available literature, having taken into consideration the specificity and resources of a given country.

The guidelines present the current management of the disease, which may be modified and altered in justifiable cases and after a detailed analysis of the clinical situation, which in turn might lead to future updates of the recommendations. Both, the patient and the treatment always require an individualized approach. Also, it is possible to apply other than recommended, and in some cases even off-label, therapies.

The available literature on the overactive bladder syndrome mostly relates to patients with mixed urinary incontinence or with urinary incontinence (UI). The authors of the present study aimed to review the up-to-date guidelines and recommendations and to analyze the management protocols for $O A B$ patients, including cases with urgency urinary incontinence.

The present recommendations are supposed to serve as a guide to therapeutic management both, for gynecologists and other specialists. Considering the continuous advances in the field of pathophysiology and pharmacotherapy, the strategies presented herein will need to be updated in due course.

Overactive bladder is a symptom complex associated with the phase of urine storage. The International Continence Society defines $O A B$ as a urinary urgency, typically with frequency and nocturia, with or without urinary incontinence. The diagnosis can be made after ruling out urinary tract infections, post-void urine retention, or changes such as cancer, urinary calculi or pelvic tumors modeling the bladder [1]. Pelvic organ prolapse (POP) may be the cause of $O A B$ symptoms in the affected women. In the experience of the authors, the diagnosis of $O A B$ should be made after excluding POP as the cause of OAB symptoms. On the other hand, numerous specialists believe that symptomatic POP should not influence the diagnosis and treatment of $O A B$.
A detailed diagnostic process is necessary to confirm the diagnosis of OAB before treatment. Also, other disorders, which might constitute the underlying causes for the reported symptoms, should be excluded. The following methods may be used in the diagnostic process: medical history, physical examination, urinalysis, urine culture, urine cytology, evaluation of post-void urinary retention, micturition diary, ultrasound examination, cystoscopy, urodynamic examination, and validated questionnaires to diagnose UI types, OAB severity, and health-related quality of life [2-4]. Importantly, a urodynamic examination is not necessary during the initial assessment and is not the essential condition to initiate treatment. The diagnostic process and test selection are tailored to the individual needs and symptoms of the patient. Guidelines for the diagnostic process of patients with $O A B$ will have been presented elsewhere.

\section{Objectives}

The aim of the Urogynecology Section of the Polish Society of Gynecologists and Obstetricians (PSGO) was to develop interdisciplinary recommendations for the management of overactive bladder (OAB) syndrome, based on the available literature reports, expert knowledge, and everyday practice. The up-to-date standards, indications and expert opinions on the clinical management of OAB are presented.

\section{MATERIAL AND METHODS}

In 2005, 2006 and 2010, the panel of PSGO experts developed guidelines for the diagnosis and treatment of urogynecologic conditions. The present publication is an update of those recommendations, based on the literature reports published between 2010 and 2019, as well as the recommendations of the American Urological Association, the European Association of Urology, and the Canadian Urological Association [2-7].

The literature, including the current international recommendations for the management of overactive bladder, urinary incontinence, urgency urinary incontinence and mixed urinary incontinence, was reviewed.

Special attention has been paid to the level of evidence and degree of recommendation of the available data sources. If the literature source seemed insufficient, expert opinions and management protocols were included.

\section{RECOMMENDATIONS}

\section{First-line treatment: behavioral therapy with} pelvic floor muscle training

According to the recommendations of the American Urological Association (AUA) [2], education of the patient (resulting in active involvement in the therapy), lifestyle modifications, and various types of behavioral therapy combined with pelvic floor muscle training (PFMT), 


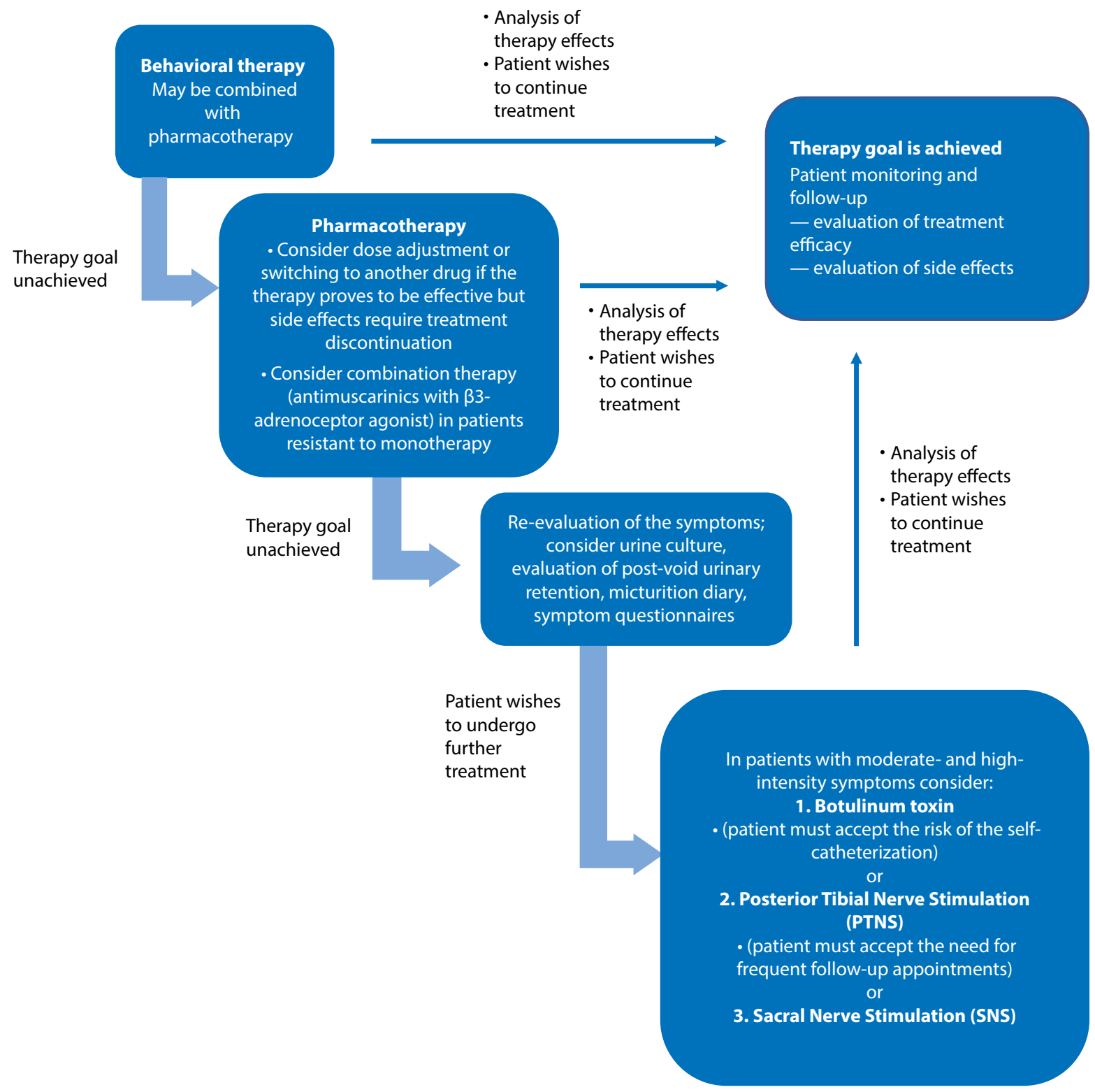

Figure 1. Management of patients with non-neurogenic overactive bladder syndrome [by M.E. Grzybowska, on the basis of Gormley EA, Lightner DJ, Burgio KL, et al. Diagnosis and Treatment of Non-Neurogenic Overactive Bladder (OAB) in Adults: an AUA/SUFU Guideline (2019). Published 2012; Amended 2014, 2019. https://www.auanet.org/guidelines/overactive-bladder-(oab)-guideline (access: 2020.01.10)]

should constitute the first-line treatment for the OAB syndrome. It is important to establish if the cognitive abilities of the patient will allow for an effective implementation of the management. From the very beginning of the therapy, the first line of treatment may be combined with pharmacotherapy, i.e., the second line. In everyday practice, both lines of treatment are often used simultaneously from the start. Patient motivation is of utmost importance as it determines lifestyle changes and strict adherence to treatment regime, which directly affects the efficacy of the treatment (Fig. 1).

Behavioral therapy includes: a) actions aimed at improving bladder function, i.e., scheduled voiding at time intervals and bladder training, allowing for gradual increase of the time intervals between voids

b) control of fluid intake and reduction of caffeine intake

c) lifestyle modifications, including weight control, cessation of smoking, and bowel regularity to prevent constipation.

Pelvic floor muscle training is an example of physical therapy used to treat OAB. In certain cases, it is also advisable to use biofeedback (real-time ultrasonography feedback, EMG-biofeedback) and electrostimulation. 
The choice of treatment depends on the symptoms and patient preferences. Most patients do not experience complete symptom resolution after the first line of treatment.

\section{Second-line treatment: oral and vaginal pharmacotherapy}

In everyday clinical practice, pharmacotherapy is typically initiated together with the first-line treatment as it is already applicable in the initial stages of OAB therapy.

After reviewing the available recommendations for $O A B$ treatment, it seems prudent to follow the guidelines issued by the American Urological Association [2], with minor modifications.

1. Oral antimuscarinics or $\beta 3$-adrenoceptor agonists are used as the second-line treatment.

2. If both, immediate release (IR) and extended release (ER) drugs are available, ER drugs are preferred due to lower risk for dry mouth.

3. In the event of insufficient symptom control and/or serious side effects after administering an antimuscarinic drug, the dose may be modified or another antimuscarinic drug or a $\beta 3$ - adrenoceptor agonist may be initiated.

4. A combination therapy (antimuscarinics combined with $\beta 3$-adrenoceptor agonists) may be considered for patients who failed on antimuscarinic or $\beta 3$-adrenoceptor agonist monotherapy.

5. Antimuscarinics are contraindicated in patients with narrow-angle glaucoma. Patients with glaucoma should be referred to an ophthalmologist for a consultation before anticholinergic drugs are considered.

6. Antimuscarinics should be used with caution in patients with impaired gastric emptying or history of urinary retention.

7. Adequate fluid intake, bowel management, dose modification or switching to another antimuscarinic or mirabegron should be recommended to patients with constipation who are satisfied with the effects of the OAB treatment with antimuscarinics before treatment discontinuation.

8. Adequate fluid intake, hydration of the oral cavity, dose adjustment or switching to another antimuscarinic or mirabegron should be recommended to patients with dry mouth who are satisfied with the effects of the OAB treatment with antimuscarinics before treatment discontinuation.

9. Before antimuscarinic therapy is initiated, patient use of other drugs with anticholinergic properties should be taken into consideration.

10. Mirabegron is effective and safe in older populations. Caution is advised when prescribing antimuscarinic drugs to frail patients.

11. Vaginal estrogen therapy may effectively alleviate $O A B$ symptoms in postmenopausal women. It is recom- mended to combine $\beta 3$-adrenoceptor agonists or antimuscarinics with estrogens in that group of patients.

12. The efficacy of pharmacotherapy may be assessed after 4-8 weeks. Then, the effects of the treatment should be evaluated, and the necessary adjustments should be introduced, if needed.

13. Patients with behavioral and pharmacologic therapy resistant $O A B$ should be referred to a specialist for further diagnostic procedures and therapeutic options.

\section{Third-line treatment: botulinum toxin and neuromodulation (posterior tibial nerve stimulation and sacral nerve stimulation) Botulinum toxin}

1. Patients with first- and second-line therapy resistant $O A B$ may be offered bladder wall injection of botulinum toxin A.

2. Patients should be informed about the limited duration of drug action and the risk for both, urinary tract infections and the need for self-catheterization (it is important to ensure the patient will cooperate and be willing to perform it, if necessary). The patient is required to report for post-void residual volume evaluation after the procedure.

3. The next bladder wall injection of botulinum toxin should be performed no sooner than three months after the pervious injection.

\section{Posterior tibial nerve stimulation (PTNS)}

In some patients, posterior tibial nerve stimulation (PTNS) may be used as third-line treatment. Transcutaneous PTNS is performed by a physiotherapist using adhesive surface electrodes. Percutaneous needle PTNS, performed by a physician, consists in stimulation with a slim needle electrode. In both cases, the electrodes are placed just above the medial condyle of the ankle.

\section{Sacral nerve stimulation (SNS)}

Sacral nerve stimulation (SNS) may be offered as third-line treatment to carefully selected patient populations with severe therapy resistant $O A B$ symptoms or those who are not eligible for second-line treatment but are willing to undergo surgery.

\section{Fourth-line treatment}

Augmentation cystoplasty or other types of urine diversion may be considered in rare and complicated cases of therapy resistant $O A B[2]$.

\section{Patient care}

Care and monitoring should be exercised during therapy to assess patient adherence to their treatment recommen- 
dations and efficacy of the therapy, or to consider other therapeutic options.

\section{Additional therapeutic procedures}

Indwelling catheters (transurethral, suprapubic, etc.) are not recommended in the management of $O A B$ due to the unfavorable risk-to-benefit ratio, with some exceptions [2].

As for manual therapy, the following techniques may be used: myofascial relaxation of the pelvic floor muscles and the lumbar-pelvic-iliac complex, joint mobilization/manipulation of the spine and the pelvis, and nerve neuromobilization. Manual therapy allows the normalization of pelvic floor and anterolateral abdominal wall muscle tone, which affects nerve conduction within the pelvis. The literature offers limited amount of data on the matter. Based on the expert knowledge and experience of the authors of the present study, manual therapy is a useful tool in OAB therapy.

\section{OVERVIEW OF THE RECOMMENDATIONS}

First-line treatment: behavioral therapy combined with pelvic floor muscle training

Actions improving the urinary bladder function

Timed voiding (at fixed intervals) - initiated by the affected patients or their caretakers - improves urinary continence, especially in older people with cognitive impairment (LE1b - level of evidence) [3].

Bladder training, typically combined with pelvic floor muscle training, is one of the basic elements of behavioral therapy. It gradually extends the time intervals between voiding, increases the bladder volume and reduces the number of urgency urinary incontinence (UUI) episodes (LE1b). The goal of the bladder training is for the patient to adhere to a voiding schedule, with gradually delayed voiding (by 15-30 minutes/week) until the goal of a 2-3-hour interval is achieved. Bladder training is used to correct urination habits. Combined with an anticholinergic and/or $\beta 3$-agonist therapy, bladder training may be a more effective way of dealing with the symptoms of frequency and nocturia than any of these therapies alone (LE1b) [3].

According to a Cochrane analysis of 23 studies and 3685 patients, symptom resolution was more frequently observed in patients receiving antimuscarinics as compared to bladder training alone ( $\mathrm{RR} 0.74,95 \% \mathrm{Cl} 0.61-0.91$ ), and in patients receiving antimuscarinics in combination with bladder training than bladder training alone (RR 0.57, 95\% Cl 0.38-0.88) [8].

\section{Fluid intake management}

Caffeine is found in beverages such as coffee, tea and cola. Reduced caffeine intake may diminish the symptoms of urgency and frequency (LE2b) [3].
Modification of fluid intake, depending on the initial balance of fluid intake and output, has been advised. In a randomized controlled trial (RCT), limitation of the fluid intake by $25 \%$ reduced the symptoms of urgency, frequency and nocturia in patients with $O A B$ [3].

Caution should be exercised when recommending fluid restriction, as this strategy is often self-initiated by the affected patients to reduce the symptoms, before seeking medical help. Minimum daily fluid intake should be approximately $1500 \mathrm{~mL}$ or $30 \mathrm{~mL} / \mathrm{kg}$ of body weight. In order to reduce the symptoms of nocturia, patients can be advised to limit their fluid intake after 6 p.m. (or 3-4 hours before bedtime) and to redirect fluid intake to the morning and afternoon hours $[4,9]$.

\section{Lifestyle modification}

In RCT, an $8 \%$ weight reduction in obese women resulted in a $42 \%$ reduction in the episodes of UUI as compared to $26 \%$ in the control group $[2,10]$. The literature offers reports which confirm that the increase in the body mass index (BMI) corresponds to the increase in the incidence of UUI. Obesity $\left(\mathrm{BMI}>30 \mathrm{~kg} / \mathrm{m}^{2}\right.$ ) is believed to be an independent risk factor for $\mathrm{OAB}[3,11,12]$.

Smoking cessation seems to be weakly correlated with symptom alleviation in patients with urinary frequency $[3,11]$. Nicotine, being an irritant, is considered a risk factor for $O A B$ symptoms in both, former and current smokers (LE3) [13].

The literature offers a considerable number of reports on higher prevalence of chronic constipation in patients with $\mathrm{OAB}[4,14]$. Charach et al., demonstrated that the treatment of constipation reduces the symptoms of urgency and frequency in older patients (LE4) $[4,15]$. However, according to the recommendations of the European Association of Urology (EAU), no evidence supports the alleviation of OAB symptoms after reduction of constipation [3]. High-fiber diet is standard medical approach to the management of constipation $[3,4]$.

\section{Pelvic floor muscle training}

Pelvic floor muscle training combined with urgency suppression techniques is often based on biofeedback (real-time ultrasonography feedback, EMG-biofeedback) with electrostimulation. The patients learn how to respond to urgency, which in turn reduces its intensity and delays the need to void. Six to ten quick pelvic contractions may be performed. If done correctly, and in the absence of parasympathetic and sympathetic dysfunction, they allow the detrusor to be temporarily relaxed. The contractions must be performed at optimal times to ensure optimal benefit (LE3) $[4,16]$.

\section{Summary}

Although most patients do not experience complete symptom resolution after behavioral therapy, significant 
Table 1. Recommendation grade for behavioral therapy [31]

\begin{tabular}{|l|l|}
\hline $\begin{array}{l}\text { Therapeutic method } \\
\begin{array}{l}\text { Lifestyle modifications (BMI reduction, smoking cessation, } \\
\text { adequate diet, fluid management, bowel management) }\end{array}\end{array}$ & A-C \\
\hline \begin{tabular}{l} 
Bladder training, scheduled voiding \\
\hline
\end{tabular} & B \\
\hline
\end{tabular}

$\mathrm{BMI}$ - body mass index

Table 2. Recommendation grade for physiotherapy [31]

\begin{tabular}{|l|l|}
\hline Physiotherapeutic method & Grade \\
\hline Pelvic floor muscle training & A \\
\hline Pelvic floor muscle training with biofeedback & B \\
\hline Electrostimulation & B \\
\hline Posterior tibial nerve stimulation (PTNS) & A \\
\hline
\end{tabular}

reduction in symptom intensity and improved quality of patient life have been reported. The absence of side effects which might accompany the pharmacotherapy in the next stages of treatment is an important benefit. Eight to twelve weeks is the optimal duration of behavioral therapy, after that time the effects of the treatment should be evaluated and modified, if necessary [2].

Promotion of healthy habits associated with the functioning of the lower urinary tract, including the bladder, should become an element of routine medical care. Lifestyle modifications and other behavioral techniques should always be discussed with the patient, not only to optimize treatment results but also to educate the patient. The grades of recommendations for behavioral and physiotherapy are presented in Tables 1 and 2.

\section{Second-line treatment: pharmacological therapy \\ 1. Oral medications}

Pharmacotherapy of OAB aims to reduce urgency, frequency, and urgency urinary incontinence, thus improving the quality of patient life. Increased 'warning time', i.e., time from the onset of the urgency to void or incontinence, is one of the most important outcomes of the drug therapy. Currently, antimuscarinic drugs and $\beta 3$-adrenoceptor agonist (mirabegron) are the most used medications in OAB therapy. Combination pharmacotherapy which uses drugs with different mechanisms of action alleviates $O A B$ symptoms more effectively as compared to monotherapy, with a comparable rate of side effects, and is recommended in patients with insufficient clinical response. An ideal medication should be safe, effective, well-tolerated, and the patients should comply with the treatment regime for the required amount of time.

The following antimuscarinic drugs are available for $O A B$ treatment: trospium, oxybutynin, tolterodine - im- mediate release (IR) and extended release (ER), fesoterodine, darifenacin, and solifenacin. Their mechanisms of action and half-life are presented in Table 3. All the above- mentioned medications have a high grade (Grade A) of recommendation, though some of them are not currently available in Poland. The effects of various antimuscarinics were compared in a systematic review and the conclusions are presented below. The efficacy and side effects of the therapy were evaluated. The daily number of micturitions, urgency and leakage episodes were analyzed, as well as patient-reported subjective assessment of the treatment efficacy. Most of the available studies analyzed the treatment efficacy after a relatively short period of time -12 weeks.

\section{Conclusions from the Cochrane review [17]}

Out of immediate release drugs, tolterodine is preferred over oxybutynin - despite similar efficacy rates - due to the lower risk for side effects, especially dry mouth. The recommended dose is $2 \mathrm{mg}$ twice daily, but $1 \mathrm{mg}$ may be equally effective, with a lower risk for side effects. Extended-release medications are preferred due to significantly reduced risk for mucosal dryness. Tolterodine ER should be the drug of choice compared to oxybutynin and tolterodine IR (LE1a). Fesoterodine demonstrated better effectiveness as compared to tolterodine ER but was associated with higher therapy discontinuation rates due to its adverse effects and (mainly) dry mouth. The recommended dose of solifenacin is $5 \mathrm{mg}$ daily and may be increased to $10 \mathrm{mg}$ daily, with elevated risk for dry mouth. Solifenacin was more effective and had lower rates of dry mouth as compared to tolterodine IR (LE1a). Solifenacin (10 mg) and tolterodine $(8 \mathrm{mg}$ ) were more effective than their doses of $5 \mathrm{mg}$ and $4 \mathrm{mg}$, respectively $[4,17]$.

\section{Drug characterization Oral medications Oxybutynin}

Oxybutynin has a mixed action. It blocks the calcium channel, and has an anticholinergic as well as a local anesthetic effect, although the latter is relevant only in case of intravesical instillation therapy. Oxybutynin is a non-selective antagonist of the muscarinic $(\mathrm{M})$ receptors, with higher affinity for $M 1$ and $M 3$ receptor subtypes than M2. M3 receptors are in the salivary glands, which is the reason for high incidence of dry mouth reported by patients using immediate-release oxybutynin [18]. Only a small number of patients continue the treatment for longer than six months due to the side effects (dry mucous membranes, constipation, blurred vision, somnolence, etc.) $[18,19]$.

Oral drugs with extended release and the transdermal patches and gels are available, but not in Poland. The transdermal route allows to lower the total dose and 


\begin{tabular}{|c|c|c|c|c|}
\hline International name & Half-life & Mechanism of action & Dosing & $\begin{array}{l}\text { Grade of } \\
\text { recommendation }\end{array}$ \\
\hline \multicolumn{5}{|l|}{ Antimuscarinic drugs } \\
\hline Trospium & $18.3 \mathrm{~h}$ & Non-selective anticholinergic action & $2 \times 20 \mathrm{mg} /$ day & A \\
\hline Oxybutynin & $2 \mathrm{~h}$ & $\begin{array}{l}\text { Non-selective anticholinergic } \\
\text { action (higher affinity for M1 and } \\
\text { M3 than M2) } \\
\text { blocks the calcium channel } \\
\text { Local anesthetic effect }\end{array}$ & $3 \times 5 \mathrm{mg}$ & A \\
\hline Tolterodine & $\begin{array}{l}\text { 2-3 h } \\
\text { 5-HMT (Tolterodine metabolite) } \\
\text { 3-4 h }\end{array}$ & Non-selective anticholinergic action & $\begin{array}{l}2 \times 1-2 \mathrm{mg} \\
\text { Extended release: } \\
1 \times 2-4 \mathrm{mg}\end{array}$ & A \\
\hline Fesoterodine & $\begin{array}{l}\text { Pro-drug } \\
\text { Metabolized in the serum to } \\
5-\mathrm{HMT} \\
7-9 \mathrm{~h}\end{array}$ & Non-selective anticholinergic action & $1 \times 4-8 \mathrm{mg}$ & A \\
\hline Darifenacin & $12 \mathrm{~h}$ & M3 & 7.5 or $15 \mathrm{mg} /$ day & A \\
\hline Solifenacin & $45-68 h$ & $\mathrm{M} 2, \mathrm{M} 3$ & $1 \times 5-10 \mathrm{mg}$ & A \\
\hline \multicolumn{5}{|l|}{$\beta 3$-adrenoceptor agonist } \\
\hline Mirabegron & $50 \mathrm{~h}$ & $\beta 3$-adrenoceptor agonist & $50 \mathrm{mg} / \mathrm{day}$ & A \\
\hline \multicolumn{5}{|l|}{ Other } \\
\hline Estrogens & & & & C \\
\hline Botulinum toxin & & & $\begin{array}{l}100 u \\
200 u\end{array}$ & A \\
\hline Resiniferatoxin, Capsaicin & & & Intravesical & C \\
\hline Antidiuretic Desmopressin & & & $\begin{array}{l}\text { Indicated in } \\
\text { nocturnal polyuria }\end{array}$ & A \\
\hline a-adrenergic receptor blocker & & & - & C \\
\hline
\end{tabular}

5-HMT - 5-hydroxymethyl tolterodine metabolite

leads to fewer dose-related side effects, increasing therapy continuation rates.

The drug penetrates the blood-brain barrier and may cause cognitive disorders so it should not be used in older patients (LE2b) [3].

\section{Trospium chloride}

Trospium chloride has an anticholinergic non-selective effect on the muscarinic receptors. It does not penetrate the blood-brain barrier, so it does not negatively affect the cognitive functions of the patient. Trospium chloride has a documented effect in the reduction of smooth muscle tension, among others in the urogenital and gastrointestinal tract, allowing for the relaxation of the detrusor muscle and reduction of the uncontrolled detrusor contractions [20]. Trospium efficacy has been demonstrated, both compared to the placebo and other anticholinergics. After 12 weeks of therapy ( $20 \mathrm{mg}$ twice daily) with trospium, mean voided volume increased by $36 \mathrm{~mL}$, whereas mean number of micturitions decreased by three per day and urgency leakage episodes by two per day [20, 21]. In a long-term (52 weeks) study, the efficacy of trospium was like oxybutynin, but with better overall tolerance [22].

\section{Tolterodine}

The parent drug, tolterodine, and its active metabolite, 5-hydroxymethyl tolterodine (5-HMT), are responsible for the effect. Tolterodine has low lipophilicity, which is the reason for its very limited penetration into the central nervous system and no adverse effects on the cognitive functions. It exhibits non-selective activity against the $\mathrm{M}$ receptor subtypes and has a higher affinity for the bladder than for the salivary glands [19]. The use of tolterodine resulted in a significantly reduced number of micturitions and urgency incontinence episodes (LE1a) in various randomized trials. After 12 weeks of therapy, symptom reduction was as follows: UUI - $80 \%$, urgency - 78\%, nocturnal frequency $-40 \%$, and daytime frequency - 30\% [23].

\section{Fesoterodine}

Fesoterodine, a non-selective anticholinergic, is a prodrug which is hydrolyzed to 5 -hydroxymethyl tolterodine 
after oral administration. Fesoterodine is a specific, but non-selective, oral antimuscarinic which acts as a competitive antagonist of muscarinic receptors. 5-HMT is an active metabolite, same as the metabolite formed from tolterodine. Part of 5-HMT is metabolized in the liver, but $>15 \%$ of the administered dose is eliminated unchanged with the urine. The dose-dependent clinical effect of fesoterodine has been confirmed but it was associated with increased adverse effects [24]. After 12 weeks of therapy with fesoterodine, mean daily number of micturitions decreased by 2.2 , urgency episodes by 3.5, and urgency urinary incontinence episodes by almost 2 , whereas mean voided volume increased by $33 \mathrm{~mL}$. No statistically significant reduction in the number of nocturia episodes was observed. In comparison to tolterodine ER, fesoterodine was statistically significantly more effective in reducing the number of urgency incontinence episodes and increasing the voided volume [25]. Fesoterodine does not prolong the QT/QTc interval, either at therapeutic or higher doses [19].

\section{Darifenacin}

Darifenacin has an 11-fold higher affinity for M3 than for $\mathrm{M} 2$ receptor subtypes. Its inhibitory activity of bladder contraction is comparable to that of atropine, at the same time demonstrating a 5-fold lower affinity for the muscarinic receptors in the salivary glands. Darifenacin was developed as a controlled-release preparation to address the inconvenience of multiple dosing per day. It is metabolized in the liver by the P450 cytochrome, is moderately lipophilic, and has no negative impact on the cognitive functions. Darifenacin is an M3-selective receptor antagonist, however, its role in developing constipation symptoms has been increasingly reported. After a two-year follow-up, 20.9\% of the patients reported constipation as compared to $7.9 \%$ in the placebo group, and $5.6 \%$ were required to use fiber supplements, stool softeners or laxatives [26]. Darifenacin does not prolong the QT/QTc interval [18]. Significant improvement in $O A B$ symptom intensity was observed already after 6-8 days of therapy [27]. After 12 weeks of therapy with the dose of $7.5 \mathrm{mg}$ and $15 \mathrm{mg}$, mean daily number of micturitions decreased by 1.6 and 1.7 , urgency episodes by 2 , and urgency incontinence episodes by 4.0 and 4.7 , respectively. Darifenacin did not significantly impact the number of nocturia episodes [28].

\section{Solifenacin}

Solifenacin is a competitive inhibitor of the muscarinic M3 receptor and has low affinity for other $M$ receptors (M2 and M1). Solifenacin has higher affinity for the urinary bladder than for the salivary glands. It has a long half-life, and its slow pharmacokinetics is associated with steady efficacy and reduced side effects. Solifenacin is metabolized in the liver via the cytochrome P450 system. First significant therapeutic effects may be observed as early as on day 7 of therapy, with the maximum effect after 28 days. Randomized controlled trials demonstrated the efficacy of solifenacin to be higher as compared to placebo or tolterodine. In the STAR study, after 12 weeks of therapy with $5 \mathrm{mg}$ of solifenacin/day, mean daily number of micturitions decreased by 2.5 , urgency episodes by 3.1 , and urgency incontinence episodes by 1.5 . Solifenacin at the dose of $5 \mathrm{mg}$ was more effective in reducing the number of urgency and urgency incontinence episodes and was associated with lower pad use as compared to $4 \mathrm{mg}$ of tolterodine ER. At the endpoint of the study, $59 \%$ of solifenacin and $49 \%$ of tolterodine ER users did not experience UUI episodes, and the difference was statistically significant $[24,29]$.

In the group of patients with multiple sclerosis and after spinal injuries, $10 \mathrm{mg}$ of solifenacin improved the urodynamic parameters, including an increase in the maximum cystometric capacity of the bladder (by $134 \mathrm{~mL}$ ) as compared to the placebo group (by $5 \mathrm{~mL}$ ) [30].

\section{Mirabegron}

Mirabegron is a $\beta 3$-adrenoceptor agonist. The sympathetic nervous system regulates the urine storage phase, and the $\beta$-adrenergic receptors present in the bladder mediate the relaxation of the detrusor and foster urine accumulation. There are three $\beta$ receptor subtypes: $\beta 1, \beta 2, \beta 3$. Approximately $97 \%$ of the $\beta$-adrenergic receptors in the urinary bladder are $\beta 3$ receptors [31]. Stimulation of $\beta 3$-adrenergic receptors increases bladder capacity without changing the micturition pressure or residual volume. In consequence, $\beta 3$-adrenoceptor agonist increases bladder capacity without affecting the contraction amplitude during micturition [32]. The recommended daily dose is $50 \mathrm{mg}$, with $25 \mathrm{mg}$ for patients with severe renal impairment (creatinine clearance $15-29 \mathrm{~mL} / \mathrm{min}$ ) or moderate liver impairment.

Four large, randomized trials demonstrated mirabegron efficacy in reducing $O A B$ symptoms as compared to placebo. In a study by Khullar et al. [33], after 12 weeks of therapy with $50 \mathrm{mg}$ of mirabegron, mean daily number of micturitions decreased by 1.9 , episodes of urinary incontinence by 1.6 , and of urgency by 2.3 , while mean voided volume increased by $24 \mathrm{~mL}$. The incidence of treatment-related adverse events (hypertension, urinary tract infection, headache, nasopharyngitis) was similar in the mirabegron and the placebo groups. Additional analysis revealed a similar efficacy of mirabegron as far as the number of incontinence episodes and micturitions was concerned, both in OAB patients with no history of antimuscarinic therapy (treatment naïve) and those who had discontinued prior antimuscarinic therapy [34]. The SYNERGY I and II studies confirmed higher efficacy of the combination therapy (solifenacin and mirabegron) as 
compared to the monotherapy. The combination therapy additionally decreased mean daily number of micturitions by $0.1-0.5$ and of incontinence episodes by $0.4-0.5$, and increased mean voided volume by another $13-16 \mathrm{~mL}$ per micturition [35].

\section{Antidepressants}

Imipramine is an antidepressant used in the treatment of $O A B$ but is currently unavailable in Poland [36]. It exerts a complex pharmacological impact through its antimuscarinic activity as well as serotonin and noradrenaline reuptake blocking properties. Imipramine has an indirect a-adrenergic effect, thus promoting detrusor relaxation and causing an increase in the intraurethral pressure [37].

Duloxetine is a norepinephrine and serotonin reuptake inhibitor, and weakly inhibits dopamine reuptake. Duloxetine increases the activity of the urethral sphincters in the urine storage phase [19]. The Onuf nucleus is a distinct group of motor neurons, located in anterior horns of the spinal cord in the sacral segment, and is the origin of the pudendal nerve. Through the pudendal nerve, the Onuf nucleus innervates the urethral striated muscles. Noradrenaline and serotonin potentiate the glutaminergic stimulation of the motor neurons, increasing striated muscle contraction [19].

Most research so far has focused on the use of duloxetine to treat stress urinary incontinence, but few reports concerned its beneficial effect in OAB therapy. Duloxetine reduces the daily number of micturitions and urgency episodes and improves the quality of patient life, while mean voided volume remains unchanged (LE4). The efficacy of duloxetine therapy has been confirmed in patients with detrusor overactivity and mixed urinary incontinence. In light of its efficacy in treating depression, duloxetine may present a therapeutic option for patients with depression and concomitant OAB symptoms (off-label use, the drug is not registered for urinary incontinence in Poland) [36].

\section{Management of nocturia with concurrent overactive bladder}

Desmopressin (DDAVP, deamino-D-arginine vasopres$\sin$ ) is a synthetic analogue of vasopressin and exhibits antidiuretic activity through vasopressin V2 receptors, affecting water reabsorption in the renal tubules. Desmopressin is used in the treatment of nocturia caused by nocturnal polyuria [3]. The recommended daily dose is $25 \mu \mathrm{g}$ for women ( $50 \mu \mathrm{g}$ for men) of desmopressin lyophilizate, administered sublingually, one hour before bedtime. Food may reduce drug strength and effect duration. Some studies support the efficacy of desmopressin for treating nocturia in patients with $\mathrm{OAB}$. A randomized trial compared the use of combination therapy ( $25 \mu \mathrm{g}$ of desmopressin and $4 \mathrm{mg}$ of tolterodine ER) versus tolterodine monotherapy. After 12 weeks of therapy, a significant difference in the nocturnal urine volume and prolonged time between the initial sleep point and the first episode of nocturia were observed in the desmopressin group of patients treated for $O A B$ and nocturnal polyuria.

Administration of desmopressin may be considered in patients affected by nocturia with concurrent $O A B$ to reduce the number and volume of nocturnal micturitions [38].

\section{Therapy continuation}

Numerous studies demonstrated low continuation rates of antimuscarinic therapy, mainly due to patient-reported lack of results and adverse effects. Wagg et al. [39], reported the following results for therapy continuation after 12 months: $35 \%$ - solifenacin, $28 \%$ - tolterodine ER, $26 \%$ - trospium, 24\% - tolterodine IR, 22\% - oxybutynin IR, and $17 \%$ - darifenacin [39]. However, after 24 months, the rates of therapy continuation ranged from 6 to 12\% [40]. According to the literature, mirabegron has a significantly longer time to therapy discontinuation as compared to antimuscarinics. After 12 months of therapy, 38\% of the patients continued mirabegron. Mean time to mirabegron and tolterodine ER discontinuation was 169 and 56 days, respectively. Factors promoting therapy discontinuation in $O A B$ patients included: younger age ( $<60$ years), insufficient information about the purpose of treatment, exceedingly high expectations about the therapy effects, reluctance to use chronic pharmacotherapy, or significant alleviation of OAB symptoms [19].

\section{Cardiovascular effects}

Drug selection for OAB therapy needs to include the possible effect of chronic pharmacotherapy on the cardiovascular system [41]. The safety profile of antimuscarinics has been confirmed by numerous studies. Unfortunately, the risk for developing drug-induced cardiac events and symptoms such as increased heart rate (HR), prolonged QT interval, and polymorphic ventricular tachycardia is a cause for some concern [42]. The $M 2$ receptors are predominant muscarinic receptor subtypes expressed in the heart and they play an important role in the maintenance of the heart rate and cardiac output. M2 receptor blockade in the sinus node, the heart's natural pacemaker, increases the pulse and decreases other parameters of the vagal tone, e.g., return to resting heart rate after exertion and baroreceptor reflex response [42].

Darifenacin selectivity for $\mathrm{M} 3$ receptors is suggestive of a minor effect on the cardiovascular system. Olshansky et al., evaluated the effects of a seven-day treatment regimen with $15 \mathrm{mg} /$ day of darifenacin, $4 \mathrm{mg} /$ day of tolterodine and placebo in healthy participants. Tolterodine was found to significantly increase the heart rate as compared to darifenacin and placebo, while darifenacin did not affect the heart rate as compared to placebo. The maximum increase in HR for tolter- 
odine occurred at times of maximum plasma concentration and was approximately $4 \mathrm{bpm}$ [43]. Fesoterodine was also found to cause a dose-related increase in HR. Mean change in HR for 4 and $8 \mathrm{mg}$ of fesoterodine and placebo was 3, 4 and $1 \mathrm{bpm}$, respectively [44]. As for oxybutynin, no increase in HR as compared to placebo was observed [45].

Solifenacin did not cause an increase in mean HR or mean blood pressure [46]. Trospium therapy may be associated with dose-related increase in HR. Mean increase in HR after trospium was $9 \mathrm{bpm}$ for the $20 \mathrm{mg}$ dose and $18 \mathrm{bpm}$ for the $100 \mathrm{mg}$ dose. The increase in HR was noted after 4-8 hours and disappeared 12 hours after administration. No significant effect on the blood pressure was detected, regardless of the dose [19]. In conclusion, darifenacin, solifenacin, and oxybutynin show no significant effect on HR [47].

In a study with placebo, mirabegron increased HR by 1-2 bpm [48]. A pooled analysis of clinical trial data found no proof of increased risk for cardiovascular adverse events for mirabegron or antimuscarinic therapy as compared to placebo. Cardiovascular adverse events were related to the pre-existing conditions of the patients, not the $O A B$ pharmacotherapy. No correlation between OAB treatment and increased risk for adverse cardiac events was demonstrated [49]. In the SYNERGY study, which analyzed combination therapy with mirabegron and solifenacin, no statistically significant increase in resting blood pressure was observed [50]. The analysis of the safety profile for the combination therapy with mirabegron and solifenacin revealed comparable rates of adverse cardiovascular events for both, combination and monotherapy [50].

QT-interval prolongation and its consequences result from inhibition of the cardiac hERG potassium channel [42]. Among antimuscarinics, darifenacin, fesoterodine and trospium chloride do not affect the QT/QTc interval [19, 42, 51]. Solifenacin may prolong the QT interval but not to a clinically relevant degree $(10 \mathrm{mg}$ - by 2 milliseconds, $30 \mathrm{mg}$ - three times the maximum therapeutic dose — by 8 milliseconds) [19]. The effect of tolterodine on the QT interval correlates with its plasma concentration. Tolterodine blocks hERG channels with high affinity but produces little QT prolongation clinically [42]. Data on the possible QT effects in patients using oxybutynin are limited [19, 42, 52]. Studies on mirabegron monotherapy found no effect on the QT/QTc interval, either in the study group or in the combination therapy with solifenacin or placebo [50]. Imipramine has a negative effect on the cardiovascular system; it prolongs the QTc interval and has a potent antiarrhythmic action [19].

\section{Polypharmacy and metabolism}

Polypharmacy ( $>5$ drugs) is a common phenomenon in the older populations. Drug interactions frequently involve the P450 cytochrome hepatic isoenzymes. Tolterodine, darifena- cin, solifenacin, oxybutynin, and mirabegron are metabolized by the P450 cytochrome system. Consequently, susceptibility to altered drug metabolism in case of drug interactions of medications based on hepatic metabolism is increased. Trospium is eliminated unchanged through the kidneys [19].

\section{Anticholinergic burden}

Anticholinergic burden should be considered when treating patients who use polypharmacy. Numerous drugs from other groups have an additional anticholinergic activity (antimuscarinics together with antidepressants and antihistamines constitute $>90 \%$ of medications with anticholinergic properties prescribed to patients). The additive effect of the drugs can be expressed as higher number of adverse effects (dry mouth, constipation, blurred vision, cognitive impairment) and lower effectiveness. The anticholinergic effect of the drugs is dose-dependent [53]. Various scales are used to assess the overall anticholinergic effect of the drugs [54]. The list of selected drugs with high and low anticholinergic potential is presented in Table 4 [55].

\section{Pharmacotherapy in older patients}

Mirabegron is effective and safe in older populations (LE1b). Antimuscarinics are equally effective in older patients and other age groups (LE1b). Over time, the impact of anticholinergic drugs on the cognitive functions increases with drug accumulation (LE2b). Oxybutynin may worsen cognitive functions in older patients, so it is not recommended for people over the age of 65 years (LE2b). In short-term studies, solifenacin, darifenacin, fesoterodine, and trospium were not found to cause cognitive dysfunction in older patients. Long-term antimuscarinic therapy should be used with caution in older patients, especially those at risk for developing cognitive impairment $[2,3]$.

\section{Vaginal estrogens}

The role of estrogens in $O A B$ therapy remains ambiguous and they are not included in most international guidelines. Patients with estrogen deficiency have been confirmed to be at an increased risk for $O A B$ [56]. In rat models after ovariectomy, a significant reduction in voided volume and an increase in micturition frequency were observed, and the administration of exogenous estrogen reversed these changes [57].

A systematic review of 11 randomized trials demonstrated the efficacy of estrogens versus placebo in reducing the number of frequency, nocturia, urgency, and incontinence episodes, and increasing bladder volume and bladder volume at the first sensation. These results pertained to local therapy (vaginal and intravesical). Systemic therapy was effective only in reducing the number of incontinence episodes and increasing the bladder volume at the first sensation, while at the same time intensifying the symptoms of nocturia [58]. 
Table 4. Anticholinergic drugs and their anticholinergic potential $[54,55]$

\begin{tabular}{|l|l|}
\hline Drug & $\begin{array}{l}\text { anticholinergic potential } \\
\mathbf{1} \text {-low }\end{array}$ \\
\hline Psychotropic drugs (N) & \\
\hline Amitriptyline & 2 \\
\hline Carbamazepine & 1 \\
\hline Citalopram & 1 \\
\hline Diazepam & 1 \\
\hline Fentanyl & 1 \\
\hline Fluoxetine & 1 \\
\hline Clozapine & 2 \\
\hline Quetiapine & 1 \\
\hline Lithium & 1 \\
\hline Mirtazapine & 1 \\
\hline Olanzapine & 1 \\
\hline Paroxetine & 1 \\
\hline Promazine & 1 \\
\hline Risperidone & 1 \\
\hline Trazodone & 1 \\
\hline Drugs & \\
\hline
\end{tabular}

Drugs which affect the digestive and metabolic system (A)

\begin{tabular}{l|l|}
\hline Domperidone & 1 \\
\hline Hyoscine & 2 \\
\hline Loperamide & 1 \\
\hline Ranitidine & 1
\end{tabular}

Drugs which affect the respiratory system and antiallergic drugs (R)

Cetirizine

Fexofenadine

Codeine

Loratadine

Theophylline

Drugs which affect the musculoskeletal system (M)

Baclofen

1

Tizanidine

2

Drugs which affect the urogenital system (G)

Darifenacin

Oxybutynin

2

Tolterodine

2

Drugs which affect the cardiovascular system (C)

Digoxin

1

The results of studies which compared the use of antimuscarinic drugs in combination with intravaginal estrogen versus antimuscarinic monotherapy remain conflicting. Tseng et al., demonstrated significant improvement in frequency, voided volume, and quality of life among women who received tolterodine and vaginal conjugated equine es- trogen treatment as compared to tolterodine monotherapy. Symptoms of nocturia, urgency and UUI after treatment improved as compared to baseline, but the combination therapy was not superior [59]. Serati et al. [60], analyzed a group of women with detrusor overactivity confirmed by urodynamic tests and showed no synergistic effect of $4 \mathrm{mg}$ of tolterodine ER and estriol cream in OAB therapy. Jiang et al., showed that solifenacin efficacy in reducing $O A B$ symptoms was identical in combination with vaginal estradiol and without estrogens. However, the addition of estradiol significantly improved patient-reported subjective impressions and quality of life [61].

\section{THIRD-LINE TREATMENT: BOTULINUM TOXIN AND NEUROMODULATION (POSTERIOR TIBIAL NERVE STIMULATION AND SACRAL NERVE STIMULATION) Botulinum toxin}

1. Patients with $O A B$ resistant to first- and second-line therapy may be offered onabotulinumtoxin $A$ (100 U) bladder wall injections [3].

2. Patients should be informed about the limited duration of action of the drug, the risk of urinary tract infection and the possibility of self-catheterization (make sure the patient will be cooperative). The patient is required to return for post-void residual evaluation [3].

3. The next injection should not be performed within three months. In clinical trials, the median duration of the effect was 166 days (approx. 24 weeks) [3, 62].

Onabotulinumtoxin A belongs to the A group of toxins. It is a neurotoxin which binds permanently to the neuromuscular junction, paralyzes neuromuscular conduction by fragmenting the synaptosomal-associated protein 25 (SNAP-25) and inhibiting the release of acetylcholine from the presynaptic terminal.

Onabotulinumtoxin A is used in idiopathic detrusor overactivity (IDO) at the dose of $100 \mathrm{U}$ dissolved in $10 \mathrm{~mL}$ of saline and injected into 20 points of the bladder wall above the bladder trigone $(0.5 \mathrm{~mL}$ per injection site). Different types of type $A$ botulinum toxin are currently available on the market, including those not registered for $O A B$ treatment (abobotulinumtoxin $A$ and incobotulinumtoxin $A$ ). Considerable attention should be paid to the registered indications of the drugs, especially in the absence of dose equivalence for these preparations [3].

In a randomized trial after 12 weeks of follow-up, onabotulinum significantly reduced all OAB symptoms as compared to the placebo group, decreased the daily number of UUI episodes ( -2.95 vs $-1.03 ; p<0.001)$, and positively affected the quality of patient life (positive response to treatment was reported by $62.8 \%$ of the patients as compared to $26.8 \%$ in the placebo group) [63]. UUI episodes were not 
reported by $22.9 \%$ of the patients in the onabotulinum group and $6.5 \%$ in the placebo group [62].

In a study comparing onabotulinum with antimuscarinics after 6 months of follow-up, both methods proved to be associated with a similar reduction in the frequency of UUI episodes (3.3 vs 3.4, respectively). However, complete resolution of UUI symptoms occurred in $27 \%$ of the patients in the onabotulinum group and only $13 \%$ in the antimuscarinic group ( $p=0.003)$. The onabotulinum group had significantly lower probability of dry mouth (31\% vs $46 \%$, respectively), but higher probability of urine retention ( $5 \%$ vs $0 \%$, respectively in the first 2 months of therapy) and urinary tract infections (33\% vs $13 \%$, respectively). The treatment effect was maintained in $38 \%$ of the patients after 12 months of onabotulinum therapy (LE1b) $[3,64]$.

In case of neurogenic detrusor overactivity (NDO), the recommended dose of onabotulinum is $200 \mathrm{U}$ (30 intra-detrusor muscle injections at the dose of $1 \mathrm{~mL}$ per site), in which case median duration of the drug effect is 256-295 days according to phase III studies [65].

\section{Other bladder injection protocols}

The concept of preventing vesicoureteral reflux is the main reason behind injecting the area above the trigone. However, several studies investigated other locations for bladder onabotulinum injections [19].

The studies which compared various sites of bladder injections did not demonstrate any increase either in post-void urine retention, or the rates of patients requiring self-catheterization, or the vesicoureteral reflux in cases when the injections were performed into the trigone [19]. In one study among patients with idiopathic detrusor overactivity (IDO), three types of injection sites were compared: body of the bladder (100U); body of the bladder (75U) and the trigone (25U); as well as the fundus (50U) and the trigone (50U). The success rate at three months of follow-up was $70 \%$ for the body of the bladder, $74 \%$ for the body and trigone, and $73 \%$ for the fundus and trigone. No statistically significant differences were found in success rates, number of urgency and UUI episodes, or long-term measures among the three subgroups. The incidence of adverse events was similar in the three groups. No vesicoureteral reflux was detected in any of the patients [66].

In contrast, a meta-analysis of eight studies and 419 patients with NDO and IDO revealed that trigone injections were more effective and were not associated with higher complication rate as compared to trigone-sparing injections. Injection depth did not affect the efficacy or safety of onabotulinumtoxin A [67].

The most common side effects of onabotulinumtoxin are related to the urinary tract. At 12 weeks of follow-up, uncomplicated UTI were found in $15.5 \%$ of the patients in the onabotulinumtoxin group and in $5.9 \%$ in the placebo group. Additionally, symptoms of dysuria (12.2\%), bacteriuria (5\%) and urinary retention (5.4\%) were reported. An increase in post-void residual (PVR) of $\geq 200 \mathrm{~mL}$ as compared to baseline was observed in $8.7 \%$ of the patients. No significant increase in PVR was observed in the placebo group. The rate of patients who required self-catheterization at any time during the first treatment cycle was $6.1 \%$ as compared to $0 \%$ in the placebo group [68].

\section{Posterior tibial nerve stimulation (PTNS)}

Percutaneous tibial nerve stimulation (PTNS) may be used as third-line treatment in some patients [3].

The tibial nerve is a peripheral nerve, with sensory and motor fibers. It originates from the L4-S3 spinal nerve roots, which are also responsible for the sensory and motor innervation of the urinary bladder and the pelvic floor. The PTNS effect is believed to be related to the retrograde stimulation of the sacral nerve plexus. The treatment typically consists in 12 weekly sessions, 30 min each, after which maintenance therapy sessions are recommended. The stimulation is performed percutaneously using a slim 34-Gauge needle inserted just above the medial condyle of the ankle (P-PTNS) [3].

PTNS is effective in treating therapy resistant $O A B$. It demonstrates significantly higher efficacy as compared to placebo, without serious side effects, and comparable efficacy to antimuscarinic therapy (LE1b). According to various meta-analyses, PTNS shows 37-100\% effectiveness and decreases the number of frequency, urgency, UUI and nocturia episodes [69]. Stimulation with transcutaneous electrodes (T-PTNS), whose effectiveness in reducing daytime frequency is comparable to P-PTNS, is also an available treatment modality (LE1b) [70].

P-PTNS maintenance therapy, performed approximately once a month, proved to be effective in maintaining the treatment effect for up to three years of follow-up (LE1b) [3]. It can also be conducted with adhesive skin surface electrodes (T-PTNS) in a weekly three-session regimen (30 min/ /session), (LE1b) [71].

In OAB patients, a physiotherapist may use vaginal, transrectal and transcutaneous electrostimulation (paraspinal electrostimulation of the micturition centers, non-invasive electrostimulation of the tibial or peroneal nerves). Based on the available sources, it is challenging to determine the sufficient number of sessions. Also, there is no consensus on the duration of one series of the electrostimulation. The authors of the present study recommend that the electrostimulation parameters be adjusted individually, taking into consideration the condition of the patient and symptom severity $[72,73]$. 


\section{Sacral nerve stimulation (SNS)}

SNS may be suggested as the third-line treatment to carefully selected populations of patients with severe therapy resistant $O A B$ or those not eligible for second-line treatment and willing to undergo surgery [2]. In Poland, only a handful of procedures have been performed so far so the experience is limited. The efficacy of SNS is higher if juxtaposed with the option of continuing unsuccessful conservative treatment to treat UUI (LE1b) [3].

The efficacy of SNS was demonstrated in patients with therapy resistant UUI. At six months of follow-up, 50\% of the patients after SNS implantation showed over $90 \%$ improvement as far as UUI symptoms were concerned as compared to $1.6 \%$ in the group with continuous pharmacotherapy (LE1b) [74].

In a prospective randomized study in patients resistant to therapy with at least one antimuscarinic drug, at six months of follow-up $86 \%$ of the patients in the SNS group reported improved or very much improved $O A B$ symptoms as compared to $44 \%$ in the antimuscarinic group $(p<0.001)$. The therapeutic success rate for SNS was $85 \%$ at 12 months and $82 \%$ at five years of follow-up. Therapeutic success was defined as at least $50 \%$ improvement in UUI episodes or at least $50 \%$ improvement in the daily number of micturitions, or a return to the normal daily number of micturitions ( $<8$ per day). At five years of follow-up, mean daily number of Ul episodes decreased by $2.0 \pm 2.2$ as compared to baseline $(p<0.0001)$, and complete continence was achieved in $45 \%$ of the patients. Mean daily reduction in the number of micturitions was $5.4 \pm 4.3$ ( $p<0.0001)$. At 12 months of follow-up, the most common device-related adverse events included 'undesirable' change in stimulation in $12 \%$, implant site pain in $7 \%$, and implant site infection in $3 \%$ of the patients. The cumulative five-year rate of lead-related adverse events which required reoperation after complete implantation was $22.4 \%$. Ineffectiveness of the therapeutic product was observed in $13 \%$ of the patients. At five years of follow-up, the rate of patients with device removal was $19.1 \%$ (LE1b) [75].

In a ROSETTA study, which compared SNS with injections of $200 \mathrm{U}$ of onabotulinum at six months of follow-up, patients in the onabotulinum group had higher reduction in the mean daily number of UUI episodes as compared to the SNS group ( -3.9 vs -3.3 episodes/day; $p=0.01$ ). They also reported significantly greater improvement in the Overactive Bladder Questionnaire SF, which evaluates symptom bother, and a higher level of satisfaction with the treatment. Urinary tract infections were significantly more frequent in patients from the onabotulinum group $(35 \%$ vs $11 \%, p<0.001)$ as well as the need for self-catheterization ( $8 \%$ at 1 month, $4 \%$ at 3 months, and $2 \%$ at 6 months of follow-up). The need for device revisions and removals was found in $3 \%$ of the patients. The small but significant difference in subjective and objective indices of therapy efficacy reported in that study gave rise to a heated debate about the clinical significance of the obtained results [76]. Based on that, the consensus in the European recommendations is that SNS efficacy is not superior to injection therapy with 200 units of onabotulinum at six months of follow-up (LE1b) [3].

Although SNS constitutes the third-line treatment, along with PTNS and onabotulinum, it should be treated as a higher-risk and more invasive method. Therefore, it is recommended to patients who are resistant to other methods of treatment [4].

In addition to OAB therapy, SNS is also effective in treating painful bladder syndrome, interstitial cystitis, urine retention not induced by bladder outlet obstruction, and fecal incontinence [69].

\section{SNS and magnetic resonance imaging}

SNS is a relative contraindication for magnetic resonance imaging (MRI). The magnetic field generates electric currents in the neuroelectrodes, which heats the electrodes in vivo and in vitro, and may cause nerve damage. Device removal is recommended if elective MRI is required. In newer devices, it is possible to perform a head examination under highly specified conditions [69].

\section{SUMMARY}

Before treatment commencement, it is necessary to conduct an adequate and thorough diagnostic process. If the therapy proves ineffective, the patient needs to be referred to a specialist. In selected situations, a multidisciplinary team consultation may be recommended.

Pharmacotherapy remains the gold standard in $O A B$ treatment and should not be delayed. However, the limitations and side effects of pharmacotherapy are the reasons why the search for new solutions continues. Animal studies are conducted to find new drugs to treat the $O A B$ syndrome $[19,36,77-80]$. Preclinical studies lead to the development of new drugs, which may in time find applications in clinical practice $[16,77]$.

\section{Conflict of interest}

None.

\section{REFERENCES}

1. Haylen BT, de Ridder D, Freeman RM, et al. International Urogynecological Association, International Continence Society. An International Urogynecological Association (IUGA)/International Continence Society (ICS) joint report on the terminology for female pelvic floor dysfunction. Neurourol Urodyn. 2010; 29(1): 4-20, doi: 10.1002/nau.20798, indexed in Pubmed: 19941278.

2. Gormley E, Lightner D, Burgio K, et al. Diagnosis and Treatment of Overactive Bladder (Non-Neurogenic) in Adults: AUA/SUFU Guideline. Journal of Urology. 2012; 188(6S): 2455-2463, doi: 10.1016/j.juro.2012.09.079. 
3. Burkhard FC, Bosch JLHR, Cruz F, et al. Guidelines on Urinary Incontinence. European Association of Urology. https://uroweb.org/guideline/urinary-incontinence/\#4 (10.01.2020).

4. Corcos J, Przydacz M, Campeau L, et al. CUA guideline on adult overactive bladder. Can Urol Assoc J. 2017; 11(5): E142-E173, doi: 10.5489/cuaj.4586, indexed in Pubmed: 28503229.

5. Radziszewski P, Baranowski W, Nowak-Markwitz E, et al. Wytyczne Zespołu Ekspertów odnośnie postępowania diagnostyczno- terapeutycznego u kobiet z nietrzymaniem moczu i pęcherzem nadreaktywnym. Ginekol Pol. 2010; 81: 789-793.

6. Skręt A, Kotarski J, Baranowski W, et al. Rekomendacje Polskiego Towarzystwa Ginekologicznego dotyczące profilaktyki oraz leczenia zaburzeń statyki narządów płciowych i wysiłkowego nietrzymania moczu u pacjentek zakwalifikowanych do histerektomii. Ginekol Pol. 2009; 80: 459-465.

7. Spaczyński M, Radowicki S, Rechberger T, et al. Rekomendacje Polskiego Towarzystwa Ginekologicznego w sprawie diagnostyki i leczenia nietrzymania moczu u kobiet. Ginekol Pol. 2005; 76(11): 848-854.

8. Rai BP, Cody JD, Alhasso A, et al. Anticholinergic drugs versus non-drug active therapies for non-neurogenic overactive bladder syndrome in adults. Cochrane Database Syst Rev. 2012; 12: CD003193, doi: 10.1002/14651858.CD003193.pub4, indexed in Pubmed: 23235594.

9. Wyman JF, Burgio KL, Newman DK. Practical aspects of lifestyle modifications and behavioural interventions in the treatment of overactive bladder and urgency urinary incontinence. Int J Clin Pract. 2009;63(8): 1177-1191, doi: 10.1111/j.1742-1241.2009.02078.x, indexed in Pubmed: 19575724.

10. Subak LL, Wing R, West DS, et al. PRIDE Investigators. Weight loss to treat urinary incontinence in overweight and obese women. $\mathrm{N}$ Engl J Med. 2009; 360(5): 481-490, doi: 10.1056/NEJMoa0806375, indexed in Pubmed: 19179316.

11. Hannestad YS, Rortveit G, Daltveit AK, et al. Are smoking and other lifestyle factors associated with female urinary incontinence? The Norwegian EPINCONT Study. BJOG. 2003; 110(3): 247-254, indexed in Pubmed: 12628262.

12. Zhu J, Hu X, Dong X, et al. Associations Between Risk Factors and Overactive Bladder: A Meta-analysis. Female Pelvic Med Reconstr Surg. 2019; 25(3): 238-246, doi: 10.1097/SPV.0000000000000531, indexed in Pubmed: 29528879.

13. Nuotio $M$, Jylhä $M$, Koivisto $A M$, et al. Association of smoking with urgency in older people. Eur Urol. 2001; 40(2): 206-212, doi: 10.1159/000049774, indexed in Pubmed: 11528200.

14. Coyne KS, Cash B, Kopp Z, et al. The prevalence of chronic constipation and faecal incontinence among men and women with symptoms of overactive bladder. BJU Int. 2011; 107(2): 254-261, doi: 10.1111/j.1464410X.2010.09446.x, indexed in Pubmed: 20590548.

15. Charach $G$, Greenstein $A$, Rabinovich $P$, et al. Alleviating constipation in the elderly improves lower urinary tract symptoms. Gerontology. 2001; 47(2): 72-76, doi: 10.1159/000052776, indexed in Pubmed: 11287730.

16. Burgio KL, Locher JL, Goode PS, et al. Behavioral vs drug treatment for urge urinary incontinence in older women: a randomized controlled trial. JAMA. 1998; 280(23): 1995-2000, doi: 10.1001/jama.280.23.1995, indexed in Pubmed: 9863850.

17. Madhuvrata $P$, Cody JD, Ellis $G$, et al. Which anticholinergic drug for overactive bladder symptoms in adults. Cochrane Database Syst Rev. 2012; 1: CD005429, doi: 10.1002/14651858.CD005429.pub2, indexed in Pubmed: 22258963.

18. Cartwright R, Cardozo L. Transdermal oxybutynin: sticking to the facts. Eur Urol. 2007; 51(4): 907-14; discussion 914, doi: 10.1016/j. eururo.2006.11.033, indexed in Pubmed: 17157979.

19. Andersson KE, Cardozo L, Cruz F. Pharmacological treatment of urinary incontinence. In: Abrams P, Cardozo L, Wagg A, Wein A. ed. Incontinence, 6th edition. ICUD ICS 2017: 805-958.

20. Rudy D, Cline $K$, Harris $R$, et al. Multicenter phase III trial studying trospium chloride in patients with overactive bladder. Urology. 2006; 67(2): 275-280, doi: 10.1016/j.urology.2005.08.017, indexed in Pubmed: 16461077.

21. Futyma K, Rechberger T. Nadaktywny pęcherz moczowy - nowe możliwości terapeutyczne. Przegląd Urologiczny. 2010; 6(64): 10-13.

22. Halaska M, Ralph G, Wiedemann A, et al. Controlled, double-blind, multicentre clinical trial to investigate long-term tolerability and efficacy of trospium chloride in patients with detrusor instability. World J Urol. 2003; 20(6): 392-399, doi: 10.1007/s00345-003-0321-8, indexed in Pubmed: 12811500.
23. Elinoff V, Bavendam T, Glasser DB, et al. Symptom-specific efficacy of tolterodine extended release in patients with overactive bladder: the IMPACT trial. Int J Clin Pract. 2006; 60(6): 745-751, doi: 10.1111/j.17421241.2006.00986.x, indexed in Pubmed: 16805763.

24. Chapple C, Fianu-Jonsson A, Indig $M$, et al. Treatment Outcomes in the STAR Study: A Subanalysis of Solifenacin $5 \mathrm{mg}$ and Tolterodine ER 4 mg. European Urology. 2007; 52(4): 1195-1203, doi: 10.1016/j. eururo.2007.05.027.

25. Herschorn S, Swift S, Guan Z, et al. Comparison of fesoterodine and tolterodine extended release for the treatment of overactive bladder: a head-to-head placebo-controlled trial. BJU Int. 2010; 105(1): 58-66, doi: 10.1111/j.1464-410X.2009.09086.x, indexed in Pubmed: 20132103.

26. Tack J, Wyndaele JJ, Ligozio G, et al. A review and additional post-hoc analyses of the incidence and impact of constipation observed in darifenacin clinical trials. Drug Healthc Patient Saf. 2012; 4: 127-139, doi: 10.2147/DHPS.S26580, indexed in Pubmed: 23055780.

27. Khullar V, Foote J, Seifu Y, et al. Time-to-effect with darifenacin in overactive bladder: a pooled analysis. Int Urogynecol J. 2011; 22(12): 15731580, doi: 10.1007/s00192-011-1522-0, indexed in Pubmed: 22006023.

28. Haab F, Stewart L, Dwyer P. Darifenacin, an M3 selective receptor antagonist, is an effective and well-tolerated once-daily treatment for overactive bladder. Eur Urol. 2004; 45(4): 420-9; discussion 429, doi: 10.1016/j.eururo.2004.01.008, indexed in Pubmed: 15041104.

29. Chapple CR, Martinez-Garcia R, Selvaggi $L$, et al. STAR study group. A comparison of the efficacy and tolerability of solifenacin succinate and extended release tolterodine at treating overactive bladder syndrome: results of the STAR trial. Eur Urol. 2005; 48(3): 464-470, doi: 10.1016/j. eururo.2005.05.015, indexed in Pubmed: 15990220.

30. Amarenco $G$, Sutory $M$, Zachoval $R$, et al. Solifenacin is effective and well tolerated in patients with neurogenic detrusor overactivity: Results from the double-blind, randomized, active- and placebo-controlled SONIC urodynamic study. Neurourol Urodyn. 2017; 36(2): 414-421, doi: 10.1002/nau.22945, indexed in Pubmed: 26714009.

31. Takahashi S, Takei M, Asakura H, et al. Clinical Guideline for Female Lower Urinary Tract Symptoms. Low Urin Tract Symptoms. 2016; 8(1): 5-29, doi: 10.1111/luts.12111, indexed in Pubmed: 26789539.

32. Nitti VW, Khullar V, van Kerrebroeck P, et al. Mirabegron for the treatment of overactive bladder: a prespecified pooled efficacy analysis and pooled safety analysis of three randomised, double-blind, placebo-controlled, phase III studies. Int J Clin Pract. 2013; 67(7): 619-632, doi: 10.1111/ijcp.12194, indexed in Pubmed: 23692526.

33. Khullar V, Amarenco G, Angulo JC, et al. Efficacy and tolerability of mirabegron, a $\beta(3)$-adrenoceptor agonist, in patients with overactive bladder: results from a randomised European-Australian phase 3 trial. Eur Urol. 2013; 63(2): 283-295, doi: 10.1016/j.eururo.2012.10.016, indexed in Pubmed: 23182126.

34. Khullar V, Cambronero J, Angulo JC, et al. Efficacy of mirabegron in patients with and without prior antimuscarinic therapy for overactive bladder: a post hoc analysis of a randomized European-Australian Phase 3 trial. BMC Urol. 2013; 13:45, doi: 10.1186/1471-2490-13-45, indexed in Pubmed: 24047126.

35. Gratzke C, van Maanen R, Chapple C, et al. Long-term Safety and Efficacy of Mirabegron and Solifenacin in Combination Compared with Monotherapy in Patients with Overactive Bladder: A Randomised, Multicentre Phase 3 Study (SYNERGY II). Eur Urol. 2018; 74(4): 501-509, doi: 10.1016/j. eururo.2018.05.005, indexed in Pubmed: 29866467.

36. Wróbel A, Kluz T, Surkont G, et al. Perspectives for the pharmacological treatment of overactive bladder syndrome. Ginekol Pol. 2017; 88(9): 504-508, doi: 10.5603/GP.a2017.0092, indexed in Pubmed: 29057437.

37. Sacomani CA, Almeida FG, Silvinato A, et al. Overactive bladder - pharmacological treatment. Rev Assoc Med Bras (1992). 2019; 65(4): 487-492, doi: 10.1590/1806-9282.65.4.487, indexed in Pubmed: 31066800.

38. Miotła P, Dobruch J, Lipiński M, et al. Diagnostic and therapeutic recommendations for patients with nocturia. Cent European J Urol. 2017; 70(4): 388-393, doi: 10.5173/ceju.2017.1563, indexed in Pubmed: 29410891.

39. Wagg A, Compion G, Fahey A, et al. Persistence with prescribed antimuscarinic therapy for overactive bladder: a UK experience. BJU Int. 2012; 110(11): 1767-1774, doi: 10.1111/j.1464-410X.2012.11023.x, indexed in Pubmed: 22409769.

40. Veenboer PW, Bosch JL. Long-term adherence to antimuscarinic therapy in everyday practice: a systematic review. J Urol. 2014; 191(4): 1003-1008, doi: 10.1016/j.juro.2013.10.046, indexed in Pubmed: 24140548.

41. Andersson KE, Sarawate C, Kahler KH, et al. Cardiovascular morbidity, heart rates and use of antimuscarinics in patients with overactive blad- 
der. BJU Int. 2010; 106(2): 268-274, doi: 10.1111/j.1464-410X.2009.090 73.x, indexed in Pubmed: 19922546.

42. Andersson KE, Campeau L, Olshansky B. Cardiac effects of muscarinic receptor antagonists used for voiding dysfunction. Br J Clin Pharmacol. 2011; 72(2): 186-196, doi: 10.1111/j.1365-2125.2010.03813.x, indexed in Pubmed: 21595741.

43. Olshansky B, Ebinger U, Brum J, et al. Differential pharmacological effects of antimuscarinic drugs on heart rate: a randomized, placebo-controlled, double-blind, crossover study with tolterodine and darifenacin in healthy participants > or $=50$ years. J Cardiovasc Pharmacol Ther. 2008; 13(4): 241251, doi: 10.1177/1074248408325404, indexed in Pubmed: 18832343.

44. Nitti VW, Dmochowski R, Sand PK, et al. Efficacy, safety and tolerability of fesoterodine for overactive bladder syndrome. J Urol. 2007; 178(6): 24882494, doi: 10.1016/j.juro.2007.08.033, indexed in Pubmed: 17937959.

45. Hussain RM, Hartigan-Go K, Thomas SH, et al. Effect of oxybutynin on the QTc interval in elderly patients with urinary incontinence. $\mathrm{Br} \mathrm{J}$ Clin Pharmacol. 1996; 41(1): 73-75, doi: 10.1111/j.1365-2125.1996.tb00161.x, indexed in Pubmed: 8824696.

46. Michel MC, Wetterauer U, Vogel M, et al. Cardiovascular safety and overall tolerability of solifenacin in routine clinical use: a 12-week, open-label, post-marketing surveillance study. Drug Saf. 2008; 31(6): 505-514, doi: 10.2165/00002018-200831060-00005, indexed in Pubmed: 18484784.

47. Cetinel B, Onal B, Gultekin $\mathrm{MH}$, et al. Which antimuscarinic agents used in the treatment of overactive bladder increase heart rate? a prospective randomized clinical trial. Int Urol Nephrol. 2019; 51(3): 417-424, doi: 10.1007/s11255-019-02090-9, indexed in Pubmed: 30725387.

48. Nitti VW, Chapple CR, Walters $C$, et al. Results of a randomized phase III trial of mirabegron in patients with overactive bladder. J Urol. 2013; 189(4): 1388-1395, doi: 10.1016/j.juro.2012.10.017, indexed in Pubmed: 23079373.

49. White WB, Siddiqui $\mathrm{E}$, Tat $\mathrm{T}$, et al. Cardiovascular safety of mirabegron: analysis of an integrated clinical trial database of patients with overactive bladder syndrome. J Am Soc Hypertens. 2018; 12(11): 768-778.e1, doi: 10.1016/j.jash.2018.08.001, indexed in Pubmed: 30181042.

50. White WB, Chapple C, Gratzke C, et al. A strategy utilizing ambulatory monitoring and home and clinic blood pressure measurements to optimize the safety evaluation of noncardiovascular drugs with potential for hemodynamic effects: a report from the SYNERGY trial. Blood Press Monit. 2018; 23(3): 153-163, doi: 10.1097/MBP.0000000000000320, indexed in Pubmed: 29578880.

51. Guay DRp. Trospium chloride: an update on a quaternary anticholinergic for treatment of urge urinary incontinence. Ther Clin Risk Manag. 2005; 1(2): 157-167, doi: 10.2147/tcrm.1.2.157.62912, indexed in Pubmed: 18360555.

52. Malhotra B, Gandelman K, Sachse R, et al. The design and development of fesoterodine as a prodrug of 5-hydroxymethyl tolterodine (5-HMT), the active metabolite of tolterodine. Curr Med Chem. 2009; 16(33): 44814489, doi: 10.2174/092986709789712835, indexed in Pubmed: 19835561.

53. Gorup E, Rifel J, Petek Šter M. Anticholinergic Burden and Most Common Anticholinergic-acting Medicines in Older General Practice Patients. Zdr Varst. 2018; 57(3): 140-147, doi: 10.2478/sjph-2018-0018, indexed in Pubmed: 29983780.

54. Welsh TJ, van der Wardt V, Ojo G, et al. Anticholinergic Drug Burden Tools/Scales and Adverse Outcomes in Different Clinical Settings: A Systematic Review of Reviews. Drugs Aging. 2018; 35(6): 523-538, doi: 10.1007/s40266-018-0549-z, indexed in Pubmed: 29736815.

55. Durán CE, Azermai M, Vander Stichele RH. Systematic review of anticholinergic risk scales in older adults. Eur J Clin Pharmacol. 2013;69(7): 14851496, doi: 10.1007/s00228-013-1499-3, indexed in Pubmed: 23529548.

56. Cheng $\mathrm{CL}$, $\mathrm{Li} J \mathrm{R}$, $\mathrm{Lin} \mathrm{CH}$, et al. Positive association of female overactive bladder symptoms and estrogen deprivation: A nationwide population-based cohort study in Taiwan. Medicine (Baltimore). 2016; 95(28): e4107, doi: 10.1097/MD.0000000000004107, indexed in Pubmed: 27428195

57. Yoshida J, Aikawa K, Yoshimura Y, et al. The effects of ovariectomy and estrogen replacement on acetylcholine release from nerve fibres and passive stretch-induced acetylcholine release in female rat bladder. Neurourol Urodyn. 2007; 26(7): 1050-1055, doi: 10.1002/nau.20438, indexed in Pubmed: 17480029.

58. Cardozo L, Lose G, McClish D, et al. A systematic review of the effects of estrogens for symptoms suggestive of overactive bladder. Acta Obstet Gynecol Scand. 2004; 83(10): 892-897, doi: 10.1111/j.0001-6349.2004. 00581.x, indexed in Pubmed: 15453881.
59. Tseng $\mathrm{LH}$, Wang $\mathrm{AC}$, Chang $\mathrm{YL}$, et al. Randomized comparison of tolterodine with vaginal estrogen cream versus tolterodine alone for the treatment of postmenopausal women with overactive bladder syndrome. Neurourol Urodyn. 2009; 28(1): 47-51, doi: 10.1002/nau.20583, indexed in Pubmed: 19089890.

60. Serati M, Salvatore S, Uccella S, et al. Is there a synergistic effect of topical oestrogens when administered with antimuscarinics in the treatment of symptomatic detrusor overactivity? Eur Urol. 2009; 55(3): 713-719, doi: 10.1016/j.eururo.2008.06.051, indexed in Pubmed: 18584946.

61. Jiang F, Zhu L, Xu T, et al. Efficacy and safety of solifenacin succinate tablets versus solifenacin succinate tablets with local estrogen for the treatment of overactive bladder in postmenopausal women--a multicenter, randomized, open-label, controlled comparison study. Menopause. 2016; 23(4): 451-457, doi: 10.1097/GME.0000000000000574, indexed in Pubmed: 26757270.

62. Nitti VW, Dmochowski R, Herschorn S, et al. EMBARK Study Group, EMBARK Study Group. OnabotulinumtoxinA for the treatment of patients with overactive bladder and urinary incontinence: results of a phase 3 , randomized, placebo controlled trial. J Urol. 2013; 189(6): 2186-2193, doi: 10.1016/j.juro.2012.12.022, indexed in Pubmed: 23246476.

63. Chapple C, Sievert KD, MacDiarmid S, et al. OnabotulinumtoxinA 100 $\mathrm{U}$ significantly improves all idiopathic overactive bladder symptoms and quality of life in patients with overactive bladder and urinary incontinence: a randomised, double-blind, placebo-controlled trial. Eur Urol. 2013; 64(2): 249-256, doi: 10.1016/j.eururo.2013.04.001, indexed in Pubmed: 23608668.

64. Visco AG, Brubaker L, Jelovsek JE, et al. Pelvic Floor Disorders Network, Pelvic Floor Disorders Network, Pelvic Floor Disorders Network. Anticholinergic therapy vs. onabotulinumtoxina for urgency urinary incontinence. N Engl J Med. 2012; 367(19): 1803-1813, doi: 10.1056/NEJMoa1208872, indexed in Pubmed: 23036134.

65. Summary of Product Characteristics Botox ${ }^{\oplus}$. https://pub.rejestrymedyczne.csioz.gov.pl/ProduktSzczegoly.aspx?id=20166 (28.03.2020).

66. Kuo HC. Comparison of effectiveness of detrusor, suburothelial and bladder base injections of botulinum toxin a for idiopathic detrusor overactivity. J Urol. 2007; 178(4 Pt 1): 1359-1363, doi: 10.1016/j. juro.2007.05.136, indexed in Pubmed: 17706718.

67. Jo JKi, Kim KN, Kim DW, et al. The effect of onabotulinumtoxinA according to site of injection in patients with overactive bladder: a systematic review and meta-analysis. World J Urol. 2018; 36(2): 305-317, doi: 10.1007/s00345-017-2121-6, indexed in Pubmed: 29124347.

68. Nitti V, Dmochowski R, Herschorn S, et al. OnabotulinumtoxinA for the Treatment of Patients with Overactive Bladder and Urinary Incontinence: Results of a Phase 3, Randomized, Placebo Controlled Trial. J Urol. 2017; 197(2S), doi: 10.1016/j.juro.2016.10.109.

69. Rovner $E$, Athanasiou $S$, Choo MS. Surgery for urinary incontinence in women. In: Abrams P, Cardozo L, Wagg A, Wein A. ed. Incontinence 6th edition. ICUD ICS 2017: 1741-1854.

70. Ramírez-García I, Kauffmann S, Blanco-Ratto L, et al. Efficacy of transcutaneous stimulation of the posterior tibial nerve compared to percutaneous stimulation in idiopathic overactive bladder syndrome: Randomized control trial. Neurourol Urodyn. 2019; 38(1): 261-268, doi: 10.1002/nau.23843, indexed in Pubmed: 30311692.

71. Martin-Garcia M, Crampton J. A single-blind, randomized controlled trial to evaluate the effectiveness of transcutaneous tibial nerve stimulation (TTNS) in Overactive Bladder symptoms in women responders to percutaneous tibial nerve stimulation (PTNS). Physiotherapy. 2019; 105(4): 469475, doi: 10.1016/j.physio.2018.12.002, indexed in Pubmed: 30862384.

72. Jerez-Roig J, Souza D, Espelt A, et al. Pelvic floor electrostimulation in women with urinary incontinence and/or overactive bladder syndrome: A systematic review. Actas Urol Esp. 2013; 37(7): 429-444, doi: 10.1016/j. acuroe.2012.08.015.

73. Wang AC, Chih SY, Chen MC. Comparison of electric stimulation and oxybutynin chloride in management of overactive bladder with special reference to urinary urgency: a randomized placebo-controlled trial. Urology. 2006; 68(5): 999-1004, doi: 10.1016/j.urology.2006.05.038, indexed in Pubmed: 17113893.

74. Weil EH, Ruiz-Cerdá JL, Eerdmans $\mathrm{PH}$, et al. Sacral root neuromodulation in the treatment of refractory urinary urge incontinence: a prospective randomized clinical trial. Eur Urol. 2000; 37(2): 161-171, doi: 10.1159/000020134, indexed in Pubmed: 10705194.

75. Siegel S, Noblett K, Mangel J, et al. Five-Year Followup Results of a Prospective, Multicenter Study of Patients with Overactive Bladder 
Treated with Sacral Neuromodulation. JUrol. 2018; 199(1): 229-236, doi: 10.1016/j.juro.2017.07.010, indexed in Pubmed: 28709886.

76. Amundsen $\mathrm{CL}$, Richter $\mathrm{HE}$, Menefee $\mathrm{SA}$, et al. OnabotulinumtoxinA vs Sacral Neuromodulation on Refractory Urgency Urinary Incontinence in Women: A Randomized Clinical Trial. JAMA. 2016; 316(13): 1366-1374, doi: 10.1001/jama.2016.14617, indexed in Pubmed: 27701661.

77. Wróbel AF, Kluz T, Surkont G, et al. Novel biomarkers of overactive bladder syndrome. Ginekol Pol. 2017; 88(10): 568-573, doi: 10.5603/GP.a2017.0102, indexed in Pubmed: 29192418.

78. Wróbel A, Doboszewska U, Rechberger E, et al. Blebbistatin, a Myosin II Inhibitor, Exerts Antidepressant-Like Activity and Suppresses Detrusor
Overactivity in an Animal Model of Depression Coexisting with Overactive Bladder. Neurotox Res. 2019; 35(1): 196-207, doi: 10.1007/s12640018-9948-5, indexed in Pubmed: 30155683.

79. Wróbel A, Rechberger T. The influence of Rho-kinase inhibition on acetic acid-induced detrusor overactivity. Neurourol Urodyn. 2017; 36(2): 263-270, doi: 10.1002/nau.22918, indexed in Pubmed: 26546786.

80. Wróbel A, Miziak B, Bańczerowska-Górska $M$, et al. The influence of nebivolol on the activity of BRL 37344 - the $\beta 3$-adrenergic receptor agonist, in the animal model of detrusor overactivity. Neurourol Urodyn. 2019; 38(5): 1229-1240, doi: 10.1002/nau.23993, indexed in Pubmed: 30937955. 